\title{
Diurnal cycle of the semi-direct effect from a persistent absorbing aerosol layer over marine stratocumulus in large-eddy simulations
}

\section{Ross J. Herbert et al.}

Correspondence to: Ross J. Herbert (ross.herbert@physics.ox.ac.uk)

The copyright of individual parts of the supplement might differ from the CC BY 4.0 License. 
a) $\Delta$ Cloud top (-) and base (--) height

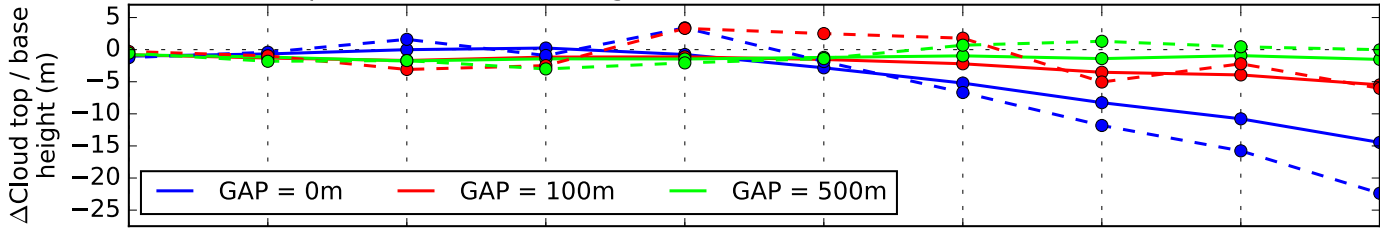

b) $\Delta$ Liquid water path

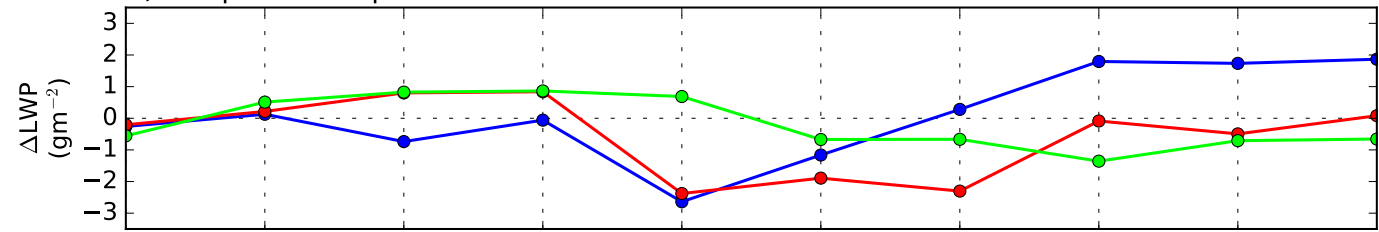

c) $\Delta$ Buoyancy flux $\left(2 \times 10^{-4} \mathrm{~m}^{2} \mathrm{~s}^{-3}\right.$ between profiles $)$

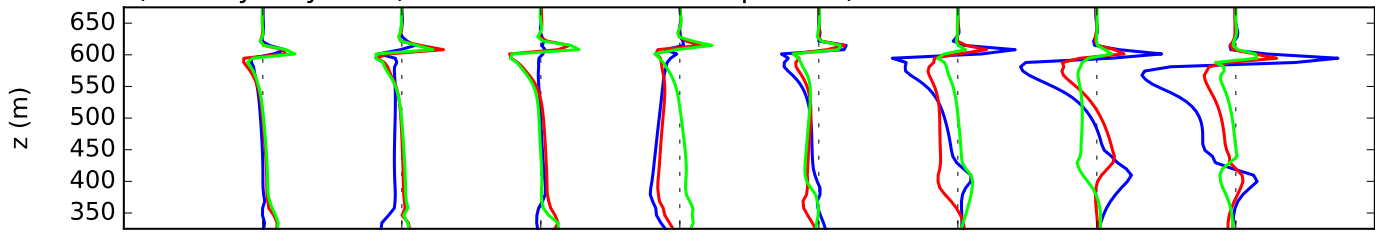

d) $\Delta$ Advected $\mathrm{q}_{t}$ tendency $\left(5 \times 10^{-3} \mathrm{gkg}^{-1} \mathrm{~ms}^{-1}\right.$ between profiles $)$

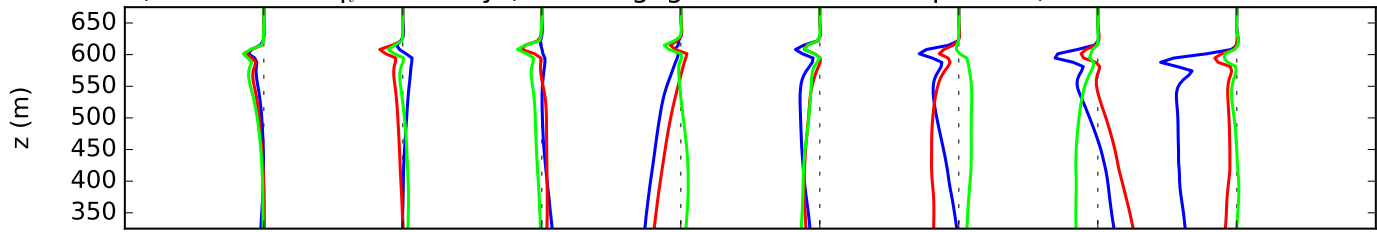

e) $\Delta$ Cloud-top LW heating rate

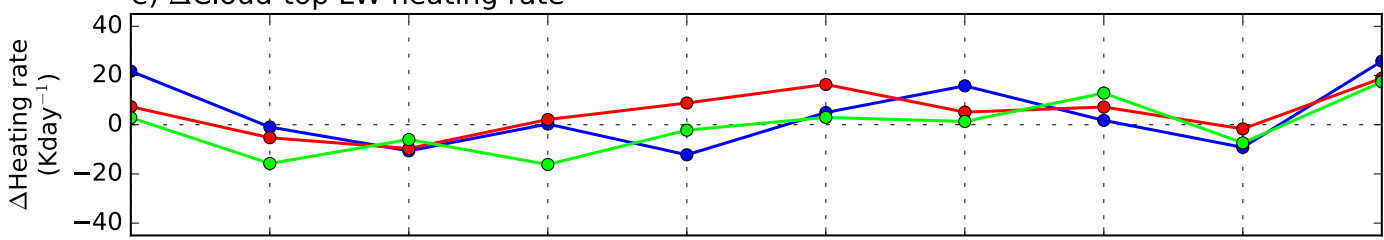

f) $\Delta \mathrm{LW} \downarrow$ net flux (10 $\mathrm{Wm}^{-2}$ between profiles)

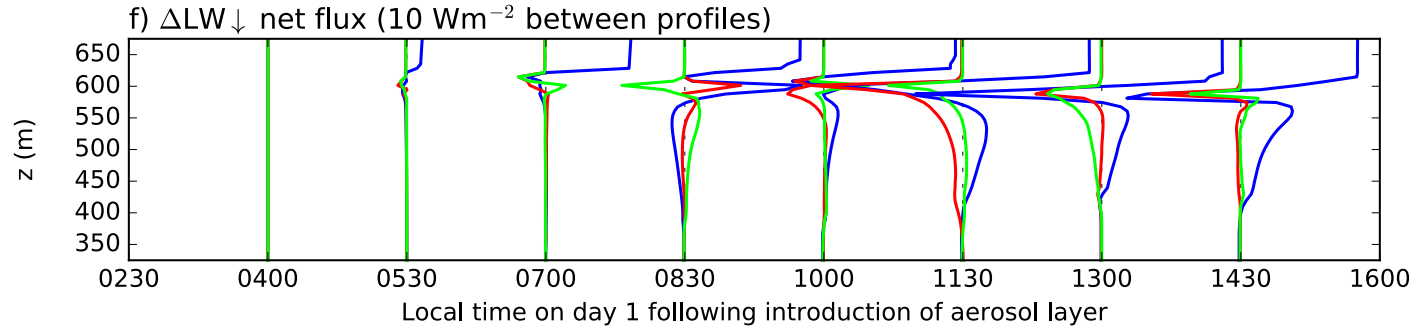

Figure S1. Response to the presence of an aerosol layer above the cloud (gap of $0 \mathrm{~m}$ in blue, $100 \mathrm{~m}$ in red, and $500 \mathrm{~m}$ in green) of a) the cloud top (solid line) and cloud base (dashed line) heights, b) the cloud liquid water path (LWP), c) profiles of the mean buoyancy flux, d) profiles of the mean advected total water content tendency, e) cloud-top longwave cooling, and f) profiles of mean longwave net flux (positive values indicate increased downward flux). The geometric thickness of the aerosol layer is $250 \mathrm{~m}$ and its optical depth is 0.2 . Data is shown for the first day following the introduction of the aerosol layer. Mean instantaneous 
profiles (shown in panels $\mathrm{c}, \mathrm{d}$, and f) for each time are centred on a value of zero, depicted by the vertical dotted lines. Each profile is separated on the $x$-axis by a constant magnitude shown above each corresponding plot.
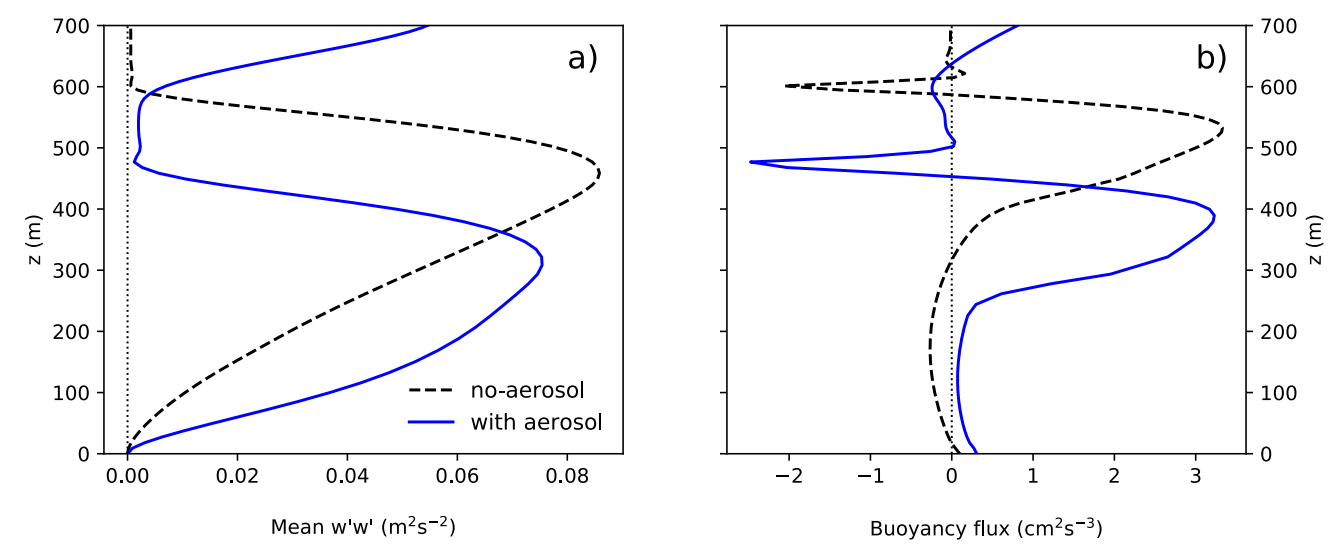

Figure S2. Domain-mean vertical profiles of a) variance in vertical velocity perturbation w'w', and b) buoyancy flux on day 13 of the simulation at 1300 local time for the no-aerosol simulation (black dashed line) and following the introduction of a layer of absorbing aerosol (blue solid line) in the base experiment ( 0 m cloud-aerosol gap, $250 \mathrm{~m}$ thick layer, and AOD of 0.2). 